\title{
PENGEMBANGAN SISTEM INVENTARIS BERBASIS QR CODE MENGGUNAKAN WEB SERVICE PADA BIDANG SARANA DAN PRASARANA STMIK STIKOM INDONESIA
}

\author{
I Nyoman Tri Anindia Putra ${ }^{1}$, I Kadek Agus Bisenna ${ }^{2}$, Ketut Sepdyana Kartini ${ }^{3}$ \\ ${ }^{1,2,3}$ Teknik Informatika, STMIK STIKOM INDONESIA \\ Denpasar, Indonesia \\ e-mail: trianindiaputra@stiki-indonesia.ac.id ${ }^{1}$
}

\begin{abstract}
Abstrak
Web service merukapan salah satu metode yang sangat bermanfaat dalam menyelesaikan permasalahan di berbagai bidang mulai dari pemerintahan, pendidikan, ekonomi, sosial, budaya. Web service dapat didefinisikan sebagai metode dalam pertukaran data yang dapat dilakukan tanpa harus memperhatikan dimana database ditanamkan dan dibuat dalam bahasa apapun. Web service mampu menunjang interoperabilitas, Sehingga web service mampu menjadi sebuah jembatan penghubung antara berbagai sistem yang ada. STMIK STIKOM INDONESIA merupakan salah satu institusi yang sudah menggunakan sistem informasi dalam memanajemen seluruh kegiatan civitas akademik yang ada dalam lingkungan institusi. Salah satunya sistem informasi inventaris, namun saat melakukan inventaris secara keseluruhan terdapat permasalahan, saat sinkronisasi data dilapangan dengan sistem, memerlukan proses panjang dan memakan waktu cukup lama. Sehingga dibuatlah pengembangan sistem inventaris berbasis QR code guna mempermudah dan mempercepat proses sinkronisasi menggunakan web service. Hasil dari penelitian terbukti dapat mempermudah serta mempercepat kinerja staff dalam melakukan sinkronisasi data pada dilapangan dengan data pada sistem.
\end{abstract}

Kata kunci: Web Service, Sistem Informasi Inventaris, QR code,

\begin{abstract}
Web service is one of the methods which is very useful in solving problems in various fields such as from government, education, economics, social, culture. Web services can be defined as methods in exchanging data that can be done without paying attention to where the database is embedded and made in any language. Web services are able to support interoperability, so that the web service is able to become a bridge between various existing systems. STMIK STIKOM INDONESIA is an institution that has used an information system in managing all activities of the academic community within the institution. One of them is the inventory information system, but when doing the overall inventory there was a problem in synchronizing data in the field with the system. It required a long process and took a long time. So that a $Q R$ code-based inventory system was developed to simplify and speed up the synchronization process using a web service. The results of the study proved to be able to facilitate and accelerate the performance of staff in synchronizing data in the field with data on the system.
\end{abstract}

Keywords : Web Service, Information System Inventory, QR code,

\section{PENDAHULUAN}

STMIK STIKOM Indonesia yang akrab dipanggil STIKI merupakan salah satu kampus IT yang ada di Bali dikenal dengan nama STMIK STIKOM Indonesia. STIKI juga merupakan salah satu 
perguruan tinggi swasta dibidang teknologi informasi di Bali dengan jenjang program strata satu (S1). Dalam proses bisnisnya mendukung civitas akademik dikerjakan dengan komputer beserta sistem informasi. Dari pengelolaan data mahasiswa, krs, yudisium, perpustakaan sampai dengan data inventaris menggunakan sistem komputer. Pengelolaan data inventaris di kampus STIKI dibawah tanggung jawab Bidang Sarana dan Prasarana yang diawasi oleh Pembantu Ketua II.

Inventaris merupakan hal yang sangat penting dalam menunjang segala kegiatan yang ada di kampus. Dimana datanya dapat digunakan sebagai acuan kapan harus membeli barang yang dibutuhkan sampai pada management seluruh barang yang ada pada instansi tersebut. Selain itu inventaris juga bisa dijadikan sebagai acuan dalam melindungi barang yang ada. Banyaknya barang sering kali menimbulkan permasalahan yang sangat riskan terjadi yaitu peletakan barang, pengawasan barang, sampai pada kehilangan yang sering terjadi, sehingga sistem inventaris sangat diperlukan untuk menunjang pekerjaan dari bidang sarana dan prasarana serta teknisi yang ada pada STMIK STIKOM INDONESIA.

Sampai saat ini, pengelolaan inventaris memang menggunakan sistem komputer, namun terdapat kendala dalam proses pencarian data sinkronisasi antara data yang ada di sistem dengan kenyataan dimana user harus mengetik nomer id yang ada pada barang sehingga memerlukan waktu untuk mengetik id barang, di dalam pengelolaannya. Hal tersebut menjadi permasalahan ketika melakukan sinkronisasi pada seluruh inventaris yang ada pada bidang Sarana dan Prasarana STIKI. Dengan permasalahan tersebut akan dikembangkan dan dibangun sistem informasi inventaris berbasis QR Code Menggunakan Webservice pada Bidang Sarana dan Prasarana STMIK STIKOM Indonesia yang dapat membantu staff teknisi dalam pengelolaan data inventaris, dan mempercepat prosesnya hal ini dikarenakan teknisi hanya perlu scan QR Code yang ada pada barang tanpa perlu mengetik nomer id barang.

\section{Permasalahan}

Berdasarkan pendahuluan yang telah dipaparkan, diperoleh permasalahan

1. banyaknya waktu yang dibutuhkan untuk melakukan proses inventarisasi terutama pada saat melakukan cek inventaris untuk dilakukan sinkronisasi antara data yang ada pada lapangan dengan data pada sistem.

2. diperlukan suatu metode yang dapat mengatasi permasalahan banyaknya waktu yang dibutuhkan dalam hal sinkronisasi data lapangan dengan data yang ada pada sistem.

\section{Manfaat}

Adapun manfaat yang peroleh pada penelitian ini yaitu

1. metode web service mampu menjadi solusi pada permasalah yang sedang terjadi di STMIK STIKOM Indonesia.

2. Memperkaya informasi terkait metode web service pada berbagai bidang salah satunya bidang manajemen inventaris.

\section{Landasan Teori \\ Sistem Inventaris}

Sistem adalah sebuah tatanan (keterpaduan) yang terdiri atas sejumlah komponen fungsional (dengan satuan fungsi dan tugas khusus) yang saling berhubungan dan secara bersama-sama bertujuan untuk memenuhi suatu proses tertentu[1].

Sistem informasi adalah kumpulan antara sub-sub sistem yang saling berhubungan yang membentuk suatu komponen yang didalamnya mencangkup input-proses-output yang berhubungan dengan pengolahan data menjadi informasi sehingga lebih berguna bagi pengguna[1]

[1]menjelaskan definisi inventarisasi, sebagai berikut : Yang dimaksud dengan inventarisasi adalah kegiatan - kegiatan yang meliputi pendaftaran, pencatatan 
dalam daftar inventaris, penyusunan atau pengaturan barangbarang milik atau kekayaan negara serta melaporkan pemakaian barang-barang kepada pejabat yang berwenang secara teratur dan tertib menurut ketentuan dan tatacara yang berlaku sehingga mempermudah dalam penyajian data kekayaan negara/pemerintah daerah baik barangbarang tetap maupun barang-barang bergerak. Jadi sistem inventaris adalah suatu tatanan yang saling terhubung dimana memuat proses pendaftaran, pencatatan dan penyusunan aset (sarana dan prasarana) yang dimiliki oleh suatu instansi bertujuan untuk mempermudah dalam penyajian data dari aset (sarana dan prasarana) suatu instansi tersebut. Inventaris adalah kegiatan melaksanakan pengurusan, penyelenggaraan, pengaturan, pencatatan dan pendaftaran barang inventaris atau hak milik. Sistem inventaris adalah sebuah sistem yang membantu dalam menjalankan proses inventarisasi (pencatatan) dalam suatu organisasi mulai dari pencatatan barang masuk, penyimpanan sampai dengan barang keluar. Hal-hal umum yang diperlukan pada inventaris mencakup:

1. Kode alat/bahan 2.

2. Nama alat/bahan

3. Spesifikasi alat/bahan (merek,tipe dan pabrik pembuat alat)

4. Sumber pemberi alat dan tahun pengadaanya

5. Tahun penggunaan

6. Jumlah atau kuantitas

7. Kondisi alat, baik atau rusak

Manfaat inventaris yaitu:

a. Mencatat dan menghimpun data aset yang dikuasahi unit organisasi / departemen

b. Menyiapkan dan menyediakan bahan laporan pertanggung jawaban atas penguasaan dan pengelolaan asset organisasi / Negara

c. Menyiapkan dan menyediakan bahan acuan untuk pengawasan aset organisasi atau Negara

d. Menyediakan informasi mengenai aset organisasi / Negara yang dikuasai departemen sebagai bahan untuk perencanaan kebutuhan, pengadaan dan pengelolaan perlengkapan departemen

e. Menyediakan informasi tentang aset yang dikuasai departemen untuk menunjang perencanaan dan pelaksanaan tugas departemen[2].

\section{Sarana dan Prasarana}

[1]Standar sarana dan prasarana pendidikan tinggi merupakan salah satu dari delapan standar pendidikan yang harus disiapkan oleh Badan Standar Nasional Pendidikan (BSNP) berdasarkan amanat yang dituangkan dalam UU RI Nomor 20 Tahun 2003 tentang Sistem Pendidikan Nasional dan PP Nomor 19 Tahun 2005 tentang Standar Nasional Pendidikan. Standar sarana dan prasarana ini disusun untuk lingkup pendidikan vokasi yang diselenggarakan oleh akademi, politeknik, sekolah tinggi, institut, dan universitas. Standar sarana dan prasarana ini mencakup: a. kriteria minimum sarana yang terdiri dari perabot, peralatan pendidikan, media pendidikan, buku dan sumber belajar lainnya, teknologi informasi dan komunikasi, serta perlengkapan lain yang wajib tersedia untuk menunjang proses pembelajaran yang teratur dan berkelanjutan, b. kriteria minimum prasarana yang terdiri dari lahan, bangunan, ruang-ruang, dan instalasi daya dan jasa yang wajib tersedia untuk menunjang proses pembelajaran yang teratur dan berkelanjutan. Menurut Kamus Besar Bahasa Indonesia[1] Sarana adalah segala sesuatu yang dapat dipakai sebagai alat dalam mencapai maksud atau tujuan. Sedangkan Menurut Kamus Besar Bahasa Indonesia [1] Prasarana adalah segala sesuatu yang merupakan penunjang utama terselenggaranya suatu proses usaha, pembangunan proyek dan lain sebagainya. Untuk lebih memudahkan membedakan keduanya. Sarana lebih ditujukan untuk benda-benda yang bergerak seperti komputer dan mesin-mesin, sedangkan prasarana lebih ditujukan untuk bendabenda yang tidak bergerak seperti gedung. 


\section{QR Code}

QR Code adalah suatu jenis image dua dimensi yang menampilkan data berupa teks. Dengan QR Code pengguna dapat mengakses suatu web lebih cepat daripada harus melakukan secara manual. QR Code dapat didaur ulang dan digunakan kembali[3].

QR Code harus pada tempat yang terang atau pencahayaan yang cukup agar kode pada QR Code terbaca oleh pemindai. QR Code mampu menampung banyak informasi dengan 7.089 karakter numerik dan 4296 karakter alfanumerik, Pemindaian QR Code juga dapat digunakan sebagai sistem keamanan untuk tempat tertentu yang boleh dimasuki orang-orang tertentu seperti ruang riset ataupun ruang pusat [3].

\section{Web Service}

Web service merupakan suatu komponen software yang merupakan selfcontaining, aplikasi modular selfdescribing yang dapat dipublikasikan, dialokasikan, dan dilaksanakan pada web. Web service adalah teknologi yang mengubah kemampuan internet dengan menambahkan kemampuan transactional web, yaitu kemampuan web untuk saling berkomunikasi dengan pola program-toprogram (P2P). Fokus web selama ini didominasi oleh komunikasi program-touser dengan interaksi business-toconsumer (B2C), sedangkan transactional web akan didominasi oleh program-toprogram dengan interaksi business-tobusiness[4].

web service dibagi menjadi dua model, yaitu web service client, dan web service server. Web service client merupakan sistem yang dibuat untuk melakukan pengaturan layanan sehingga client dapat mengakses layanan yang diberikan[5].

\section{Sistem}

Sistem dapat didefinisikan sebagai kumpulan komponen-komponen yang bekerja sama untuk tujuan bersama. Misalnya bidang orga nisasi keuangan, operasi dan pemasaran memiliki tujuan yang sama untuk mencapai tujuan perusahaan secara keseluruhan. Hal ini dapat dilihat bahwa dalam sistem, data digunakan sebagai input untuk diproses yang menghasilkan informasi sebagai output[6].

\section{Informasi}

Informasi adalah kumpulan dari beberapa fakta yang terorganisasi dan telah diproses agar memiliki nilai tambah selain nilai-nilai individual. Nilai dari informasi tersebut diantaranya bagaimana membantu pembuat keputusan mencapai tujuan organisasi mereka. Dapat membantu orang dalam organisasi melakukan tugas-tugas dengan efisien dan efektif[6].

\section{METODE}

Pengumpulan data dilakukan berdasarkan observasi dan wawancara terhadap sistem yang memang sudah ada. Adapun tahapan penelitian yang telah dilakukan pada penelitian ini, yang pertama Identifikasi Permasalahan dan kebutuhan sistem : Pada tahap ini dilakukan proses identifikasi kebutuhan yang dibutuhkan untuk mengembangkan sistem inventaris yang telah ada sehingga mempermudah kinerja dari staff terkait. Selanjutnya dilakukan pengumpulan data dan analisis data. Dalam tahap ini dilakukan analisis data-data informasi yang akan di masukan kedalam QR code dengan menggunakan Web Service. Selanjutnya dilakukan analisis design database sistem yang sudah ada pada sistem untuk di integrasikan dengan web service. Perancangan desain dapat dilihat pada gambar 1 .

\section{HASIL DAN PEMBAHASAN}

Setelah dilakukan penelitian diperoleh penambahan 2 fitur konten pada sistem informasi inventaris yang sudah ada yaitu mencetak QR code pada setiap barang yang telah masuk kedalam sistem informasi inventaris dan melakukan proses scanner QR code melalui sistem inventaris dengan menggunakan handphone.Penambahan konten pertama dapat dilihat pada gambar 3 dimana admin tinggal mengklik $1 \mathrm{x}$ icon printer yang ditunjuk oleh mouse screen. dengan tulisan (Cetak All QR Code) atau 
dengan mengklik $1 \mathrm{x}$ icon printer yang ada pada gambar 3. maka label QR code untuk barang siap untuk di cetak.

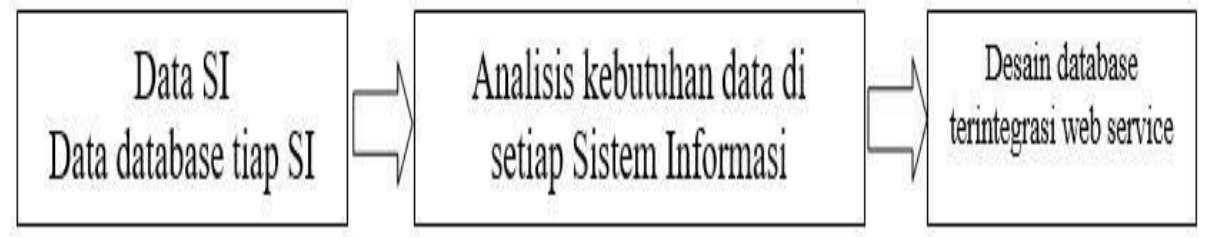

Gambar 1. Gambaran Umum Proses perancangan database

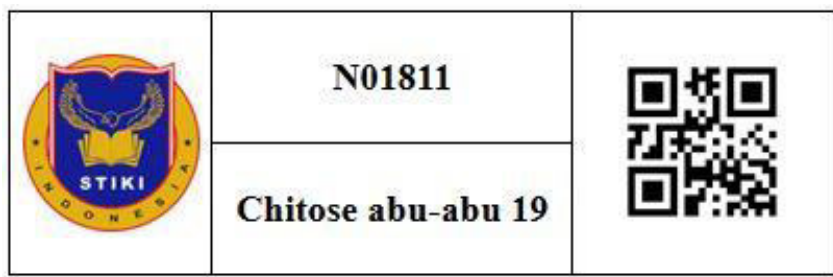

Gambar 2 Hasil Integrasi Gambar QR Code dengan Kode Barang dari Sistem Informasi Inventaris

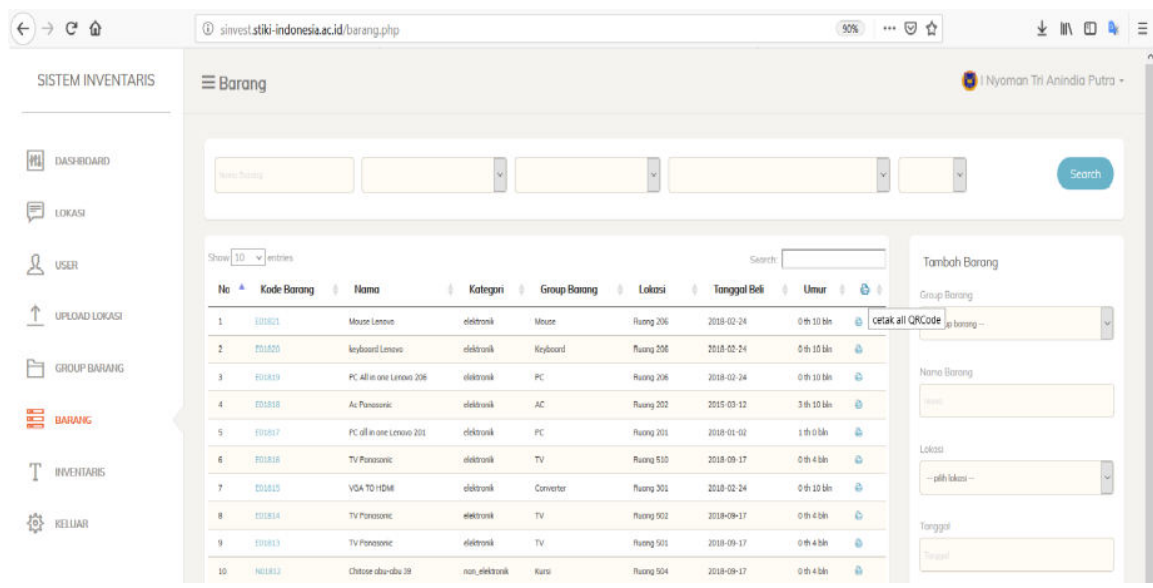

Gambar 3 Konten Fitur untuk melakukan cetak QR Code

Pada Gambar 4 dilakukan proses scanner QR Code dengan menekan tombol Hijau maka secara otomatis Camera pada Handphone akan hidup dan tinggal melakukan proses scan. Setelah scan akan muncul nama barang tanpa harus mencari kode barang lagi.
Gambar yang telah dicetak dapat dilihat pada gambar 2 dan untuk konten kedua dapat dilihat pada gambar 4. Pada gambar 4 terdapat interface untuk melakukan proses scanner melalui handphone sehingga mempermudah kinerja staff dalam melakukan pengecekan barang baik yang ada di lapangan maupun yang ada pada sistem 


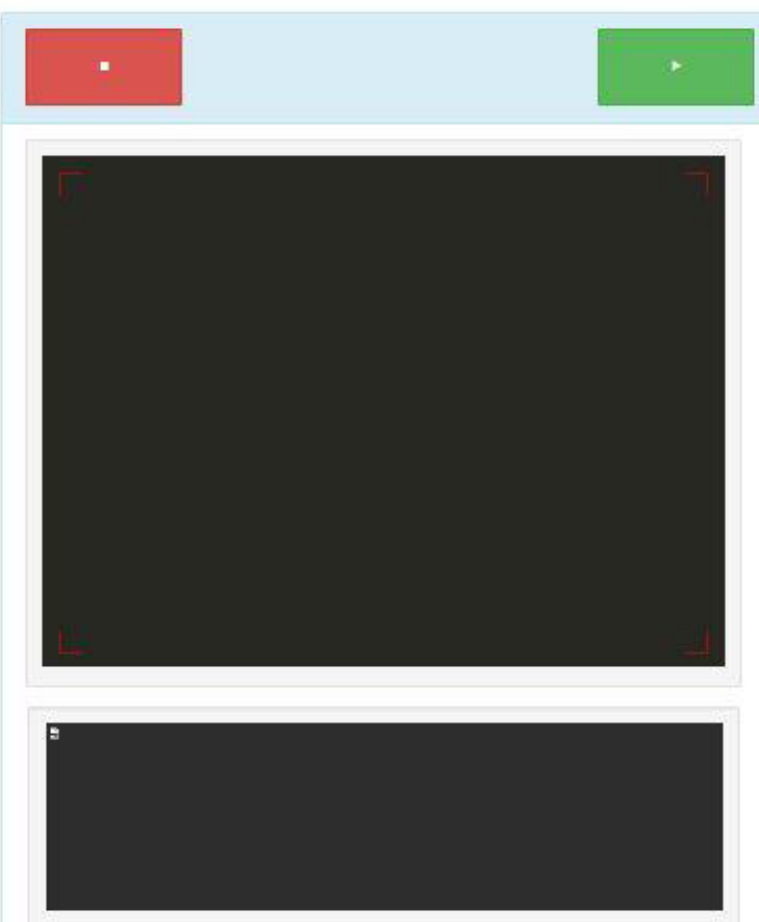

Gambar 4 merupakan tampilan untuk proses scanner QR Code menggunakan Handphone

Secara sederhana sistem yang dibuat menggunakan web service dengan menggunakan API dari Google yaitu dengan mengintegrasikan kode barang yang ada pada sistem dengan API milik Google. Dimana sistem inventaris sebagai client yang mengirimkan kode barang untuk dimasukan kedalam QR Code dengan API yang sudah disediakan oleh Google. Cuplikan Code dapat dilihat pada gambar 5.

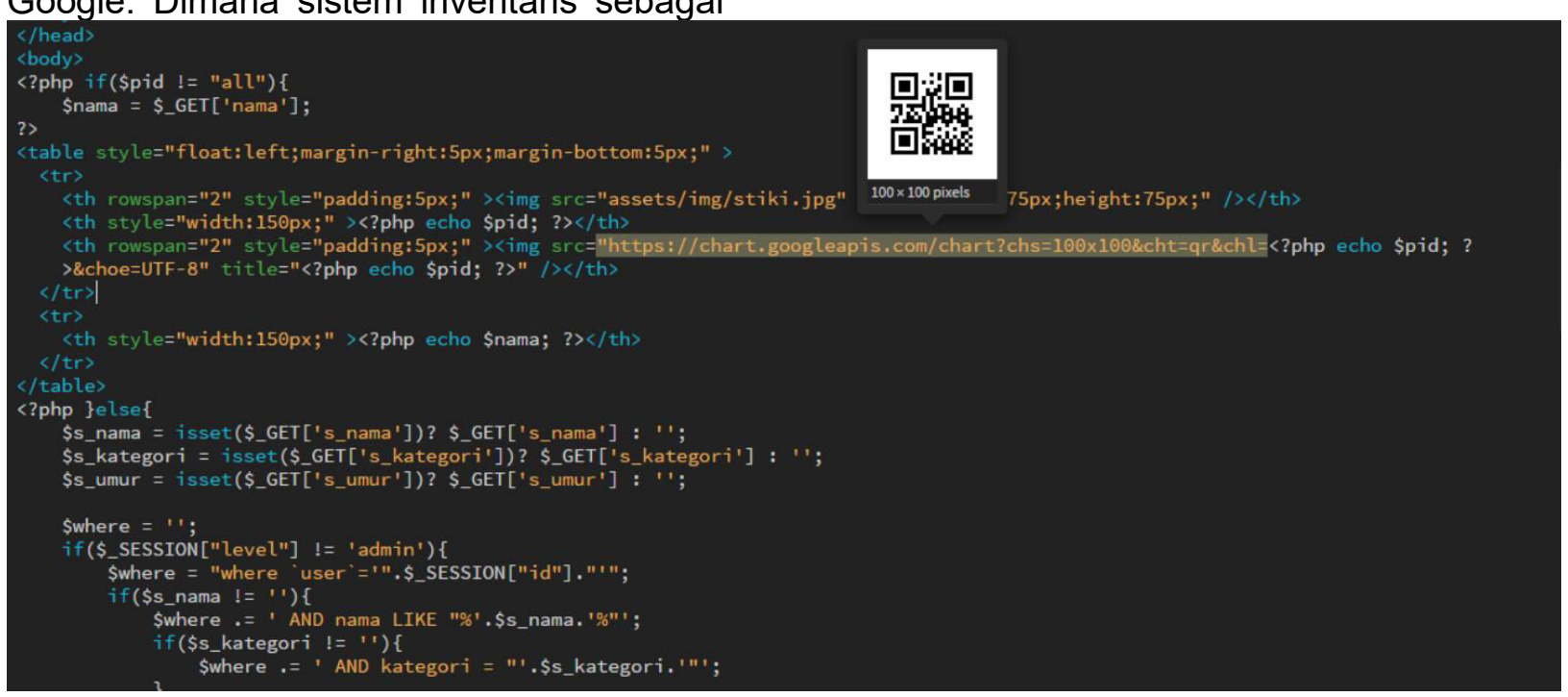

Gambar 5 cuplikan souce code akses konten QR Code dengan menggunakan Google AP

\section{PENGUJIAN SISTEM}

Pada penelitian ini dilakukan pengujian dengan cara melakukan implementasi dengan mengoperasikan sistem yang telah dibuat pada kasus yang sesungguhnya dan memperoleh hasil yang sangat baik berdasarkan waktu yang 
dibutuhkan baik dalam inventarisasi barang maupun pengecekan inventarisasi barang. hal ini dibuktikan dari pengujian dengan menggunakan studi kasus yang terjadi di lapangan yang sesungguhnya. Proses dilakukan dengan menghitung waktu mulai proses pengecekan inventarisasi baik dengan menggunakan konten QR Code maupun tanpa QR code dan diperoleh hasil yang baik dimana web service terbukti dapat mengurangi waktu yang dibutuhkan dalam proses pengecekan barang yang ada pada sistem dan di lapangan. Tabel pengujian berdasarkan studi kasus dapat dilihat pada tabel 1 dan tabel 2 , dimana tabel 1 merupakan tabel pengujian studi kasus pengecekan inventaris tanpa menggunakan sistem informasi yang sudah ditambahkan konten QR Code. Sedang kan tabel 2 merupakan tabel studi kasus dimana sistem informasi sudah menggunakan konten web service untuk melakukan pengecekan barangnya. Pada studi kasus yang pertama staff melakukan pengecekan melalui laptop yang dibawa ke kelas kelas untuk dilakukan sinkronisasi dengan database yang ada pada sistem informasi, kemudian staff mengeti kode id yang pada barang yang ada pada barang, kemudian menulis kondisi barang pada sistem. Berdasarkan pengujian studi kasus yang telah dilakukan waktu rata rata yang dibutuhkan oleh staff dalam mengecek seluruh inventaris pada suatu kelas dibutuhkan waktu sebanyak 80,3 menit. Sedangkan pada tabel 2 dilakukan pengujian studi kasus dengan menggunakan sistem inventaris yang sudah ditambahkan konten web service untuk scan QR Code dalam melakukan proses inventaris pada setiap kelas dan menghasilkan waktu yang lebih singkat dimana rata rata yang dibutuhkan untuk melakukan inventarisasi barang pada suatu kelas adalah 38 menit.

Tabel 1. Pengujian cek kondisi barang tanpa QR Code

\begin{tabular}{ccc}
\hline $\begin{array}{c}\text { Studi Kasus Cek Kondisi } \\
\text { Barang tanpa QR Code }\end{array}$ & \multicolumn{2}{c}{$\begin{array}{c}\text { Waktu yang dihabiskan dalam } \\
\text { pengecekan barang }()\end{array}$} \\
\hline Cek Inventaris Kelas 101 & 78 menit & 56 item \\
Cek Inventaris Kelas 102 & 87 menit & 63 item \\
Cek Inventaris Kelas 103 & 74 menit & 56 item \\
Cek Inventaris Kelas 201 & 81 menit & 66 item \\
Cek Inventaris Kelas 202 & 82 menit & 64 item \\
Cek Inventaris Kelas 203 & 80 menit & 63 item \\
Rata rata waktu & $\mathbf{8 0 , 3}$ Menit & \\
\hline
\end{tabular}

Tabel 2. Pengujian cek kondisi barang dengan QR Code

\begin{tabular}{ccc}
\hline $\begin{array}{c}\text { Studi Kasus Cek Kondisi } \\
\text { Barang tanpa QR Code }\end{array}$ & $\begin{array}{c}\text { Waktu yang dihabiskan dalam } \\
\text { pengecekan barang }()\end{array}$ \\
\hline Cek Inventaris Kelas 101 & 32 menit & 56 item \\
Cek Inventaris Kelas 102 & 37 menit & 63 item \\
Cek Inventaris Kelas 103 & 34 menit & 56 item \\
Cek Inventaris Kelas 201 & 42 menit & 66 item \\
Cek Inventaris Kelas 202 & 39 menit & 64 item \\
Cek Inventaris Kelas 203 & 44 menit & 63 item \\
Rata rata waktu & 38 Menit & \\
\hline
\end{tabular}

Pengujian secara black box juga dilakukan, tentunya saat perancangan dan pembuatan konten yaitu penambahan $Q R$ code dan scanner QR code yang telah berhasil di implementasikan. Hal tersebut dapat dilihat pada tabel 3. Dimana dibuat tiga skenario pengujian untuk menguji konten yang telah dibuat. Pada pengujian black box 
menghasilkan hasil yang sempurna dimana sistem yang telah dibuat berhasil berjalan dengan baik sebagai mestinya sesuai dengan perancangan yang telah dibuat saat melakukan analisis kebutuhan. Sehingga dapat disimpulkan bahwa pengujian sistem dengan menggunakan black box berhasil dan berjalan dengan baik.

Table 3 Pengujian Black Box

\begin{tabular}{l|c|c}
\hline Skenario pengujian & Berhasil & Gagal \\
\hline 1. Cetak QR Code 1 barang & $\mathrm{V}$ & \\
2. Cetak QR Code 1 Ruangan & $\mathrm{V}$ & \\
3. Scan QR Code 1 Barang & $\mathrm{V}$ & \\
\hline
\end{tabular}

\section{SIMPULAN}

Berdasarkan Penelitian yang telah dilakukan terhadap permasalahan yang ada yaitu diperlukan waktu yang relatif lama untuk melakukan pengecekan antara barang yang ada pada STMIK STIKOM Indonesia dengan Barang yang ada pada sistem inventaris dapat disimpulkan sebagai berikut:

1. Berdasarkan analisis permasalahan Web Service terbukti membantu mempercepat waktu yang dibutuhkan staff dalam mengecek inventarisasi yang ada pada sistem dan yang ada pada lapangan

2. Web service merupakan salah satu metode multifungsi yang dapat digunakan untuk menyelesaikan permasalahan tanpa harus membuat dari 0 konten yang diperlukan.

3. Analisis kebutuhan perancangan sistem sangat perlu dilakukan dengan sangat cermat untuk dapat memilih dengan baik langkah yang termudah dan tercepat dalam menyelesaikan permasalahan yang ada pada suatu studi kasus.

4. Berdasarkan parameter waktu yang telah diujikan pada studi kasus penelitian ini yaitu proses pengecekan inventarisasi pada suatu kelas terbukti dapat diselesaikan dalam waktu yang lebih singkat dengan menggunakan metode web service.

\section{SARAN}

Adapun saran yang dapat diberikan peneliti pada penelit ian kali ini :

1. Dalam menyelesaikan permasalahan tidak perlu terlalu rumit dan menggunakan metode yang sulit untuk menyelesaikan permasalahan yang ada.

2. Web Service merupakan salah satu metode yang dapat digunakan untuk menyelesaikan permasalahan, pada berbagai bidang mulai dari pendidikan, ekonomi, sosial, budaya sampai pada pemerintahan, sehingga perlu dilakukan penelitian lebih lanjut dengan menggunakan metode ini.

\section{UCAPAN TERIMAKASIH}

Ucapan terima kasih ditujukan kepada seluruh pihak yang telah membantu menyelesaikan penelitian ini.

\section{REFERENSI}

[1] R. N. Annisa and M. Ugiarto, "Sistem inventaris sarana dan prasarana di fakultas ilmu komputer dan teknologi informasi universitas mulawarman," vol. 2, no. 1, pp. 69-72, 2017.

[2] V. G. U. Yuniati Rakhel1, Arief Hidayat2, "PERANCANGAN SISTEM 
INFORMASI INVENTARIS

BERBASIS WEB MOBILE (Studi Kasus : STMIK ProVisi Semarang)," pp. 132-145.

[3] I. G. B. Jawi, "Pemindaian QR Code Untuk Aplikasi Penampil Informasi Data Koleksi Di Museum Sangiran Sragen Berbasis Android," pp. 6-8, 2015.

[4] H. Deviana, "Penerapan XML Web service Pada Sistem Distribusi Barang," vol. 6, no. 2, 2011.
[5] T. A. Cahyanto, "Penerapan Teknologi Web Service Pada Sistem Informasi Data Rekam Medis Rumah Sakit XYZ," vol. 5341, no. April, pp. 25-32, 2018.

[6] Y. Adhawiyah, N. Kumaladewi, and M. Caturutami, "( StudiKasus : Kantor Wilayah Kementerian Agama DKI Jakarta )," vol. 10, no. 2, pp. 119126, 2017. 